\title{
Brajendra K. Sharma and Girma Bireshaw (Eds): Environmentally Friendly and Biobased Lubricants
}

\author{
Ken Jones ${ }^{1}$
}

(C) Springer-Verlag Berlin Heidelberg 2016

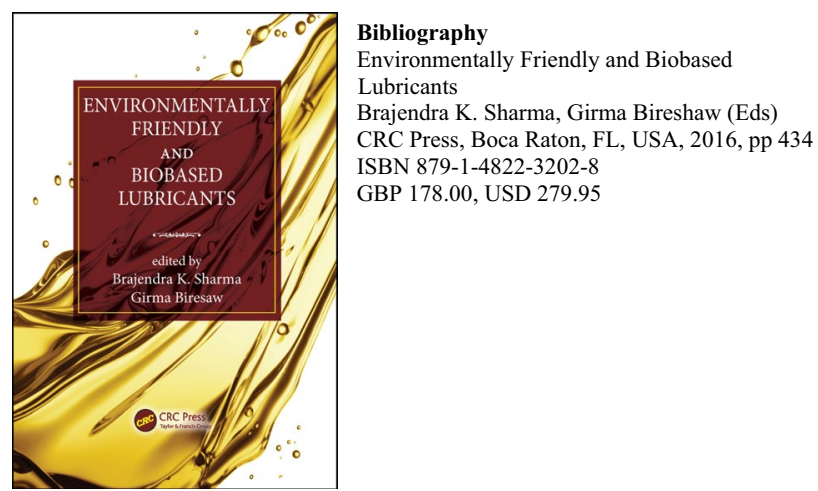

A steady predictable global growth of any product will always attract new entrants and lubricants are no exception. Environmental imperatives demand replacement of environmentally unfriendly hydrocarbons at every opportunity, but only if their performance is technically equal or better. The second factor is cost. As almost always, no attempt is made in this compilation to compare performance against cost. This subject may not be much interest to scientists, but not so accountants who hold the purse strings. They decide upon whether a company buys product $\mathrm{A}$ or product B. Their opinion is usually paramount. It is hoped that future authors might wish to address this presentational weakness. A comparison of costs against performance is not difficult, and would give readers some idea of the true worth of the products proposed, to complete what are usually purely technical reports.

There is no technical difficulty in recycling even very complex degraded mixtures, as represented by exhausted

Ken Jones

chromatographia@springer.com

1 Knutsford, Cheshire, UK internal combustion engine lubricants. The recycling process is relatively simple and very cost-effective, but overall, economics fail by the cost of collection of the used oil. In any event, synthetics are now rapidly replacing the hydrocarbon element in high-temperature applications. Furthermore, as electrically driven vehicles begin to dominate, which is predicted in the next decade, so will demand for high-temperature lubricants decline.

The book is divided into five sections, containing 23 chapters and written by 45 authors, two-thirds based in USA. Of the estimated 42 millions tons of global lubricants that will be manufactured in 2017 , only $1.7 \%$ will utilise biobased lubricants: a challenge or an opportunity? The range of biobased products presented here is comprehensive, imaginative, based on good science, and with some products having surprisingly good lubrication properties. When coupled with their biodegradability, in some situations and locations, they will clearly be a preferred choice.

There seems a little doubt that for low-temperature applications, biodegradable products could replace the conventional lubes with some success, specifically those used as emulsions with water. Several billion gallons of cutting fluid emulsions are globally used annually, at a cost up to $7-10 \%$ of the final price of the machined product. It is noticeable that this most obvious of target applications did not merit its own chapter, in what is a fairly comprehensive review of the state of the art.

Although rather a scattergun approach, the book has merit. It could usefully be read by lubricant researchers, if only to extend their knowledge of products, currently so widely ignored. 